\title{
Development, Simulation and Construction of Cost-effective GTEM Cells
}

\author{
Tinus Stander and Saurabh Sinha \\ Carl \& Emily Fuchs Institute for Microelectronics, Dept. of Electrical, Electronic and Computer Engineering \\ University of Pretoria \\ Pretoria, South Africa \\ tinus.stander@ieee.org, ssinha@ieee.org
}

\begin{abstract}
Gigahertz transverse electromagnetic (GTEM) cells are used extensively in industry for testing the impact of defined E-fields on devices sensitive to electromagnetic interference. Compared to anechoic chambers, GTEM cells are small, inexpensive and require less powerful amplifiers to achieve the same field strength. This paper presents the design, simulation and qualification of a compact GTEM cell capable of generating field strengths in excess of $600 \mathrm{~V} / \mathrm{m}$ over a $20 \times 20 \times 15 \mathrm{~cm}$ test cavity, whilst being less than $2.2 \times 1.3 \times 1 \mathrm{~m}$ in total size. Specific hybrid FEM-MLFMM simulation strategies are provided to examine high power device characteristics prior to manufacturing, including accurate modelling of absorber materials. Practical notes on manufacturing and qualification are also presented.
\end{abstract}

Keywords - Computational electromagnetics; Electromagnetic compatibility and interference; TEM cells; Test equipment.

\section{INTRODUCTION}

Gigahertz transverse electromagnetic (GTEM) cells are used extensively in industry for testing the impact of defined Efields on devices sensitive to electromagnetic interference (EMI) [1] and replacements for anechoic chambers for antenna measurements [2]. Compared to anechoic chambers, GTEM cells are small, inexpensive and require less powerful amplifiers to achieve the same field strength. GTEM cells are also capable of producing E-fields and $\mathrm{H}$-fields at higher frequencies than traditional TEM cells.

The body of literature on GTEM cell modelling is mature, with references dating back to the late 1980's. Cascaded transmission line models [3], Finite Element Method (FEM) [2], Finite Integral Time Domain (FITD) [4] [5] and Finite Integration [5], Finite Difference Time Domain (FDTD) [6], conventional method of moments (MoM) [7] have all been used successfully to simulate GTEM cells, with different strategies on model subdivision illustrated. A common feature of these is, however, that no practical notes on the construction of GTEM cells are provided. Apart from [1], some notes on the relative contribution of lumped and distributed (absorptive) termination is provided in [8], with modelling (but not measured results) of optimal feed structures shown in [4] and [10]. Practical characterization notes are provided in [6], and pulsed systems and results are shown in [9], but these systems produce E-fields below $100 \mathrm{~V} / \mathrm{m}$ and low power sources. The systems in [7] and [11] provide a more detailed design approach, but do not highlight simulation or practical manufacturing difficulties in building GTEM cells in-house. The current body of literature's upper limit of consideration on field strength in GTEM cells is $200 \mathrm{~V} / \mathrm{m}$ [12] at frequencies well below $1 \mathrm{GHz}$.

The predominant shortcoming in the current body of knowledge seem to be the absence of the Multilevel Fast Multipole Method (MLFMM) in the modelling of GTEM cells, as well as achieving high (in excess of $600 \mathrm{~V} / \mathrm{m}$ ) field strengths from compact GTEM cells and the associated difficulties in power handling and dissipation. This paper addresses both gaps in the literature, presenting a practical guide to designing, simulating and constructing compact, high field strength GTEM cells in-house with the use of hybrid FEM-MLFMM simulation techniques and cost-effective manufacturing practices

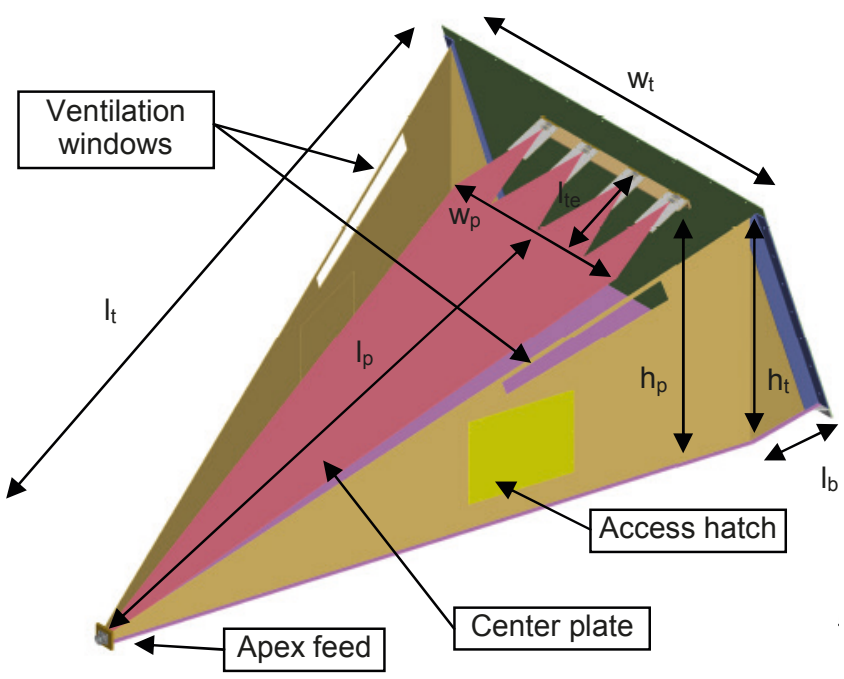

Figure 1. Computer Aided Design (CAD) model of a GTEM cell, with basic dimensions and annotations. Absorbing cones not pictured.

A list of the device requirements is provided in Table I, with the basic geometry in Fig. 1. The unique challenge of this design is not only the high E-field requirement, but also the high power handling capability required in a portable form. This necessitates accurate modelling and simulation of absorber structures, to ensure that the incident power of a $1 \mathrm{~kW}$ $\mathrm{RF}$ amplifier does not damage the device. In addition, the design, simulation and characterization of the device had to be 
TABLE 1. GTEM CELL REQUIREMENTS

\begin{tabular}{|c|c|}
\hline Operating frequency band & $0.4-1 \mathrm{GHz}$ \\
\hline Nominal dominant E-field strength (Ey) & $600 \mathrm{~V} / \mathrm{m}$ \\
\hline Max. input reflection at input port & $-10 \mathrm{~dB}$ \\
\hline Maximum variation in Ey & $\pm 3 \mathrm{~dB}$ \\
\hline Max. secondary field strength (Ex, Ez) & $-6 \mathrm{~dB}$ of Ey \\
\hline Area under test & $20 \times 20 \times 15 \mathrm{~cm}$ \\
\hline Max. GTEM cell size & $2.2 \times 1.3 \times 1 \mathrm{~m}$ \\
\hline Max. available input power & $1 \mathrm{~kW} \mathrm{CW}$ \\
\hline
\end{tabular}

completed within 200 manhours, necessitating fast and effective simulation strategies with limited computational resources. Finally, the USD $\$ 10,000$ project budget did not allow for a bought-out GTEM cell, necessitating the in-house design and construction of the device.

Since numerous source describe the theoretical synthesis of GTEM cells at length $[1,2,7,9,11]$ it will not be repeated here. To maximize the amount of absorber-covered surface area, the maximum allowable dimensions were used for the outer area of the cell. The detail of centre conductor pitch angle, transitions, support and absorber were all selected through CAD, discussed in the next section.

\section{CAD AND SIMULATION RESULTS}

\section{A. CAD strategy}

Since the manufacturing and detailed implementation of the GTEM cell was expected to affect the operation of the cell significantly, an iterative design-and-simulate approach was followed in the design of the cell. Simulation time was reduced by dividing the structure into fine discretization FEM structure at the feed where accurate modelling of small dimensions were required, whilst using the MLFMM algorithm to solve the large volume body and termination of the cell. The chosen EM simulation software, $\mathrm{FEKO}^{1}$ Suite 6.1, supports co-simulation using these techniques.

\section{B. Materials characterisation}

To increase the accuracy of the simulation model, it was decided to model the AEMI AEPV24 anechoic cones at the back of the GTEM cell into the MLFMM simulation region. For this purpose, the material properties of the cones $\left(\tan \delta_{\varepsilon}\right.$, $\tan \delta_{\mu}, \varepsilon_{\mathrm{r}}$ and $\mu_{\mathrm{r}}$ ) first had to be characterized. This was done in simulation, using an incident plane wave on an identical geometry (Fig. 2) and altering the material properties until the reflected plane wave agreed to that published by the manufacturer. These material properties were then used in further full-wave simulation.

A similar process was applied in characterizing the Eccosorb HR10 material used in the design, but here measurement data was used to estimate reflection, absorption and transmission. It was found that this material, though highly absorptive at frequencies above $18 \mathrm{GHz}$, provided $1-1.5 \mathrm{~dB}$ absorption below $1 \mathrm{GHz}$ with negligible reflection. This property allowed it to be used as absorptive buffer, absorbing some incident energy without reflecting it back to the source.
Since the dielectric supporting material inside the cell has a significant impact on the internal field distribution [5], the Eccostock SH14 material was also included in simulation. This material's dielectric properties are, however, provided by the manufacturer.

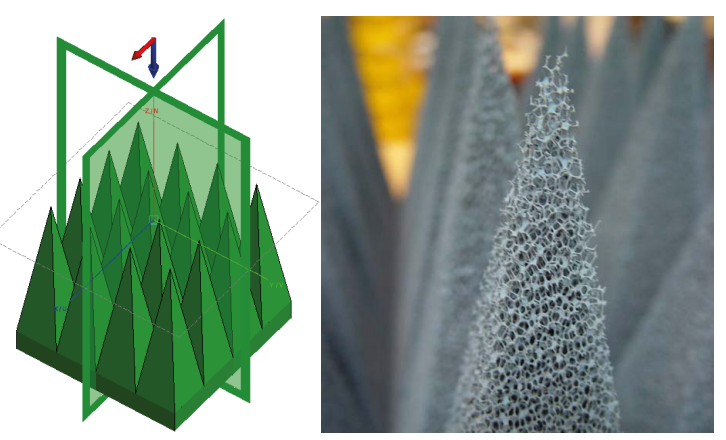

Figure 2. Simulated (left) and photographed (right) anechoic cones.

\section{FEM modeling of apex feed.}

The $1 \mathrm{GHz}, 1 \mathrm{~kW}$ excitation of the GTEM cell required that the centre plate be matched to a coaxial 7/16 DIN connector. This transition was modelled in a FEM solver, including the effects of the SH14 supporting material underneath the centre, as shown in Fig. 3. Using results from [4] and [10], dimensions for the transition were established as shown in Fig. 4. The results in Fig. 5 indicate theoretical input reflection below $-20 \mathrm{~dB}$ across the band. The termination of the simulation was an open waveguide port, the incident field of which is used to excite the MLFMM simulation.

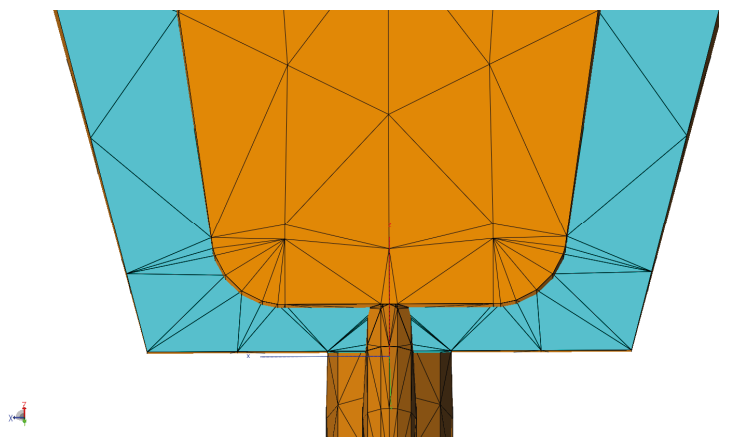

Figure 3. FEM model of apex feed using coaxial 7/16 DIN connector.

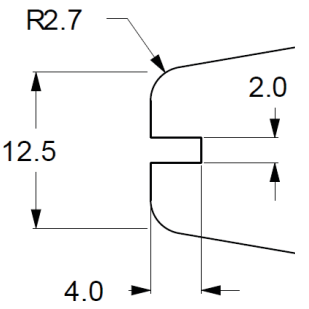

Figure 4. Final dimensions of the apex feed. The slot of length $4 \mathrm{~mm}$ is cut to fit the centre pin of the 7/16 DIN coaxial connector. 


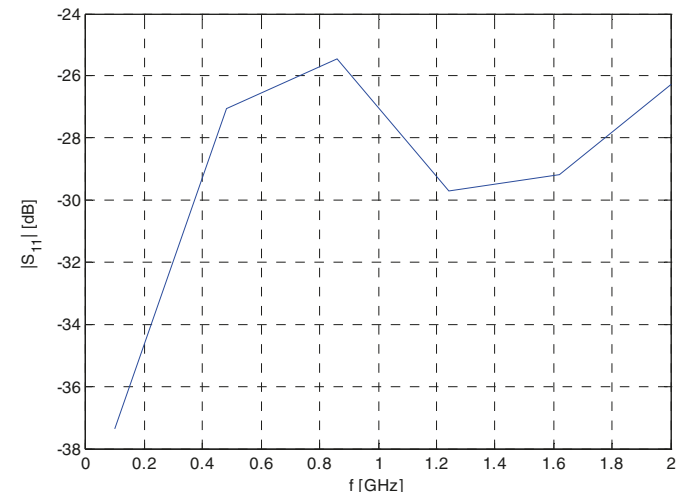

Figure 5. Simulated input reflection from the transition.

\section{Resistive and absorptive termination}

The termination of the GTEM cell through a combination of lumped resistors (through a four-way linear tapered transition) and anechoic cones was simulated by the MLFMM (Fig. 6). No significant improvement in input reflection was observed using non-linear (logarithmic, parabolic, exponential or tan) taper curves. Similarly, no significant improvement in input reflection response was observed using more than four terminations. Fewer terminations, however, yielded significantly more input reflection for linear tapers. The advantage of using fewer terminations is that high-power RF resistors are generally only available in low values (typically only $50 \Omega, 100 \Omega$ and $200 \Omega$ ). Using more terminations would lead to more parallel resistors, which would require higher resistor values to keep the termination matched to $50 \Omega$.

It was found that the resistive termination only provided $10 \mathrm{~dB}$ input reflection up to $270 \mathrm{MHz}$, after which the energy is primarily absorbed by the anechoic cones at higher frequencies. This is similar to the findings in [8]. This frequency represents the cut-off frequency of the $\mathrm{TM}_{11}$ mode at the absorption plane, indicating a transition from the dominant propagating mode from TEM to non-TEM modes.

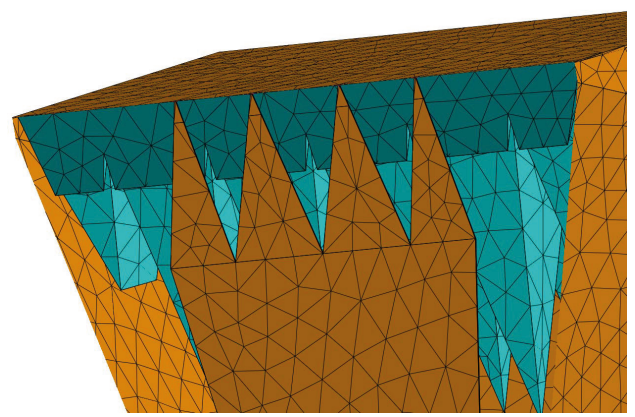

Figure 6. MLFMM model of resistive and anechoic termination.

\section{E. Combined cavity and termination simulation}

After the terminations were determined, the full cavity was used using an incident field source (extracted from the FEM simulation of the apex). The following key results were extracted from this simulation:

\section{1) Input reflection}

The full structure indicated below $-15 \mathrm{~dB}$ input reflection across the band of interest (Fig. 7). Some standing wave effects are visible due to imperfect termination.

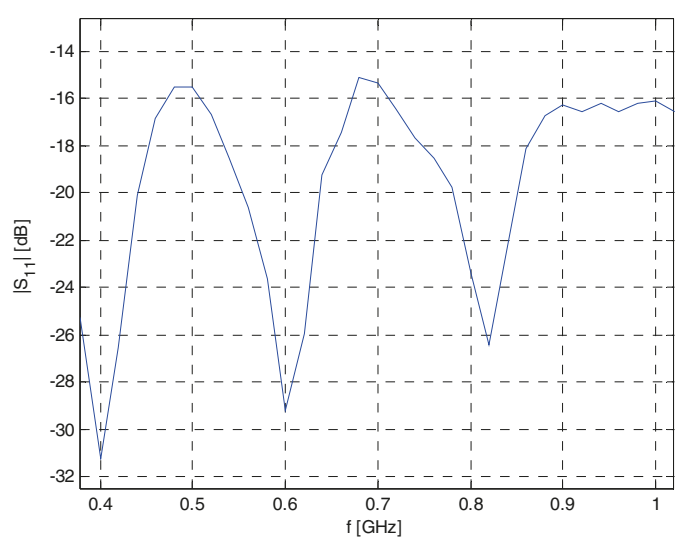

Figure 7. Full simulation model input reflection.

\section{2) Power absorption in the terminating resistors}

From Fig. 8 it is clear that only a fraction of the incident $1 \mathrm{~kW}$ energy is absorbed in the termination resistors. This means that the anechoic cones absorb most of the incident TEM wave too, placing an additional burden on their power handling capability.

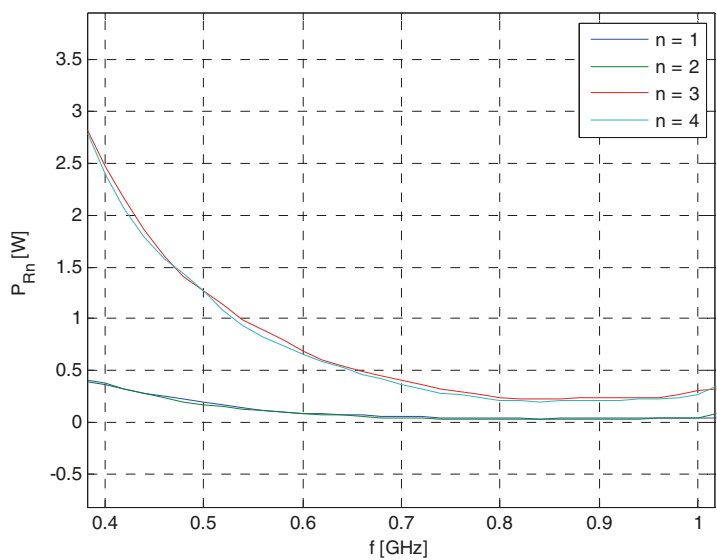

Figure 8. Power absorption in the four terminating resistors.

\section{3) Field strength}

From Figs. 9, 10 and 11, it is clear that

- The required $600 \mathrm{~V} / \mathrm{m}$ strength for $\mathrm{E}_{\mathrm{y}}$ can easily be achieved with $1 \mathrm{~kW}$ incident power.

- The $\mathrm{E}_{\mathrm{y}}$ field is dominant by more than $-6 \mathrm{~dB}$ across the designated test volume

- $\quad \mathrm{E}_{\mathrm{y}}$ is constant to within $\pm 3 \mathrm{~dB}$ across the designated test volume. 
However, Fig. 12 shows that Ey varies by as much as $\pm 3.5 \mathrm{~dB}$ off the nominal strength across the band of interest. This is due to the high pitch angle and imperfect matching. However, the required $600 \mathrm{~V} / \mathrm{m}$ is still achieved across the frequency band. The only implication is that the input power would have to be varied over frequency to maintain a nominal $600 \mathrm{~V} / \mathrm{m}$.

\section{4) Incident power}

Of most concern, however, is the incident power (as $\mathrm{W} / \mathrm{m}^{2}$ ) plotted in Fig. 13. Here, the incident $\mathrm{z}$-directed power $(\mathrm{Pz})$ is plotted at a point near the anechoic cone tips, above the centre plate. The incident power of, nominally, $13 \mathrm{~kW} / \mathrm{m}^{2}$ (for $1 \mathrm{~kW}$ incident power) is beyond the $1.5 \mathrm{~kW} / \mathrm{m}^{2}$ power handling capability of the AEPV24 material. The requirement, therefore, exists to attenuate the incident power above the plate by at least $9.4 \mathrm{~dB}$, which is achievable (according to previous modelling of the Eccosorb HR10 material) by placing a minimum of 6 sheets of Eccosorb HR10 in front of the anechoic cones, on top of the centre conductor. This is a crucial result from the MLFMM simulation, having a direct impact on the GTEM cell's construction.

\section{F. Final cell geometry}

The final manufactured geometry of the GTEM cell (dimensioned in Fig. 1) is shown in Table II.

TABLE II. MANUFACTURED GTEM DIMENSIONS IN MM

\begin{tabular}{|c|c|}
\hline Total box length $l_{t}$ & 2110 \\
\hline Center plate length $l_{p}$ & 1724 \\
\hline Terminating taper length $l_{t e}$ & 280 \\
\hline Total box width $w_{t}$ & 1230 \\
\hline Center plate width $w_{p}$ & 613 \\
\hline Centre height at termination $h_{p}$ & 624 \\
\hline Total box height $h_{t}$ & 742 \\
\hline Base extension length $l_{p}$ & 225 \\
\hline Access panel size & $300 \times 300$ \\
\hline
\end{tabular}

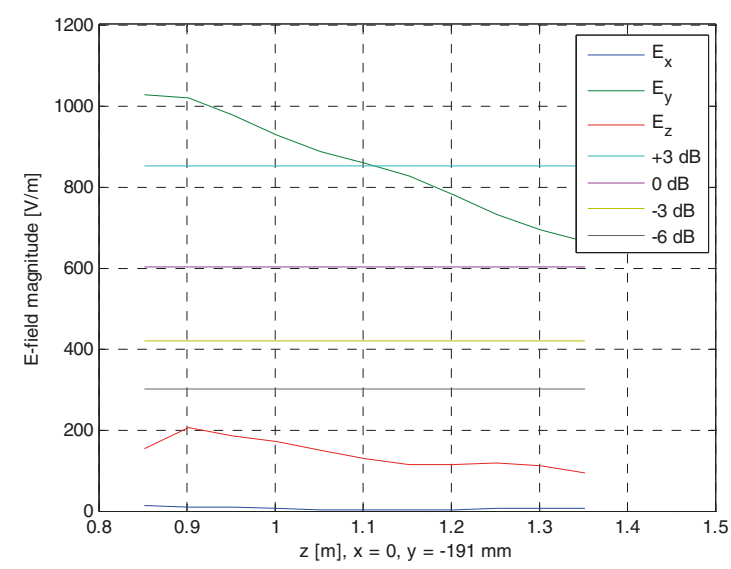

Figure 9. Nominal field strengths vs. distance from the apex $(z)$ of $E_{x}$, $\mathrm{E}_{\mathrm{y}}$ and $\mathrm{E}_{\mathrm{z}}$ at $700 \mathrm{MHz}$

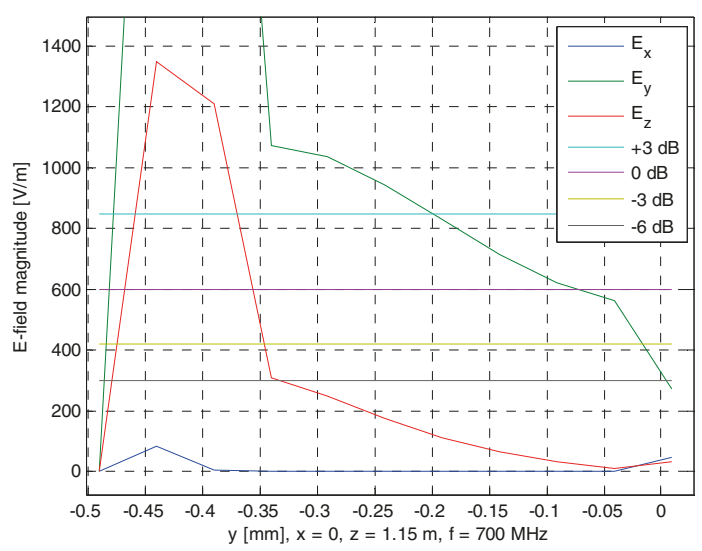

Figure 10. Nominal field strengths vs. height from the cell floor $(\mathrm{y})$ $E_{x}, E_{y}$ and $E_{z}$ at $700 \mathrm{MHz}$. Note the sudden increase at $-0.35 \mathrm{~m}$, the level of the centre conductor.

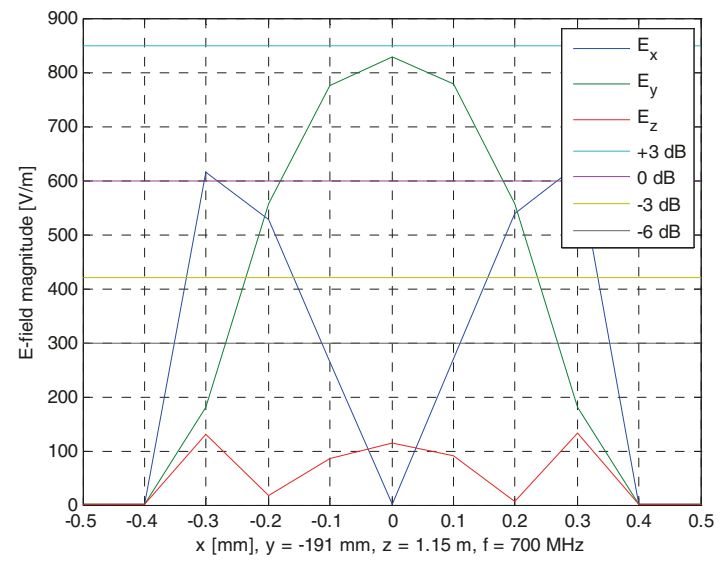

Figure 11. Nominal field strengths vs. horizontal displacement from centre $(x)$ of $E_{x}, E_{y}$ and $E_{z}$ at $700 \mathrm{MHz}$.

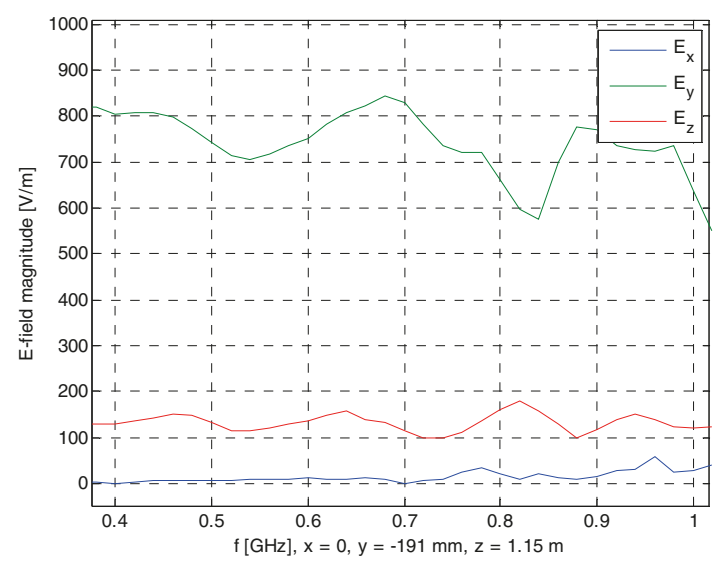

Figure 12. Nominal field strengths vs. frequency in the centre of the text volume. 


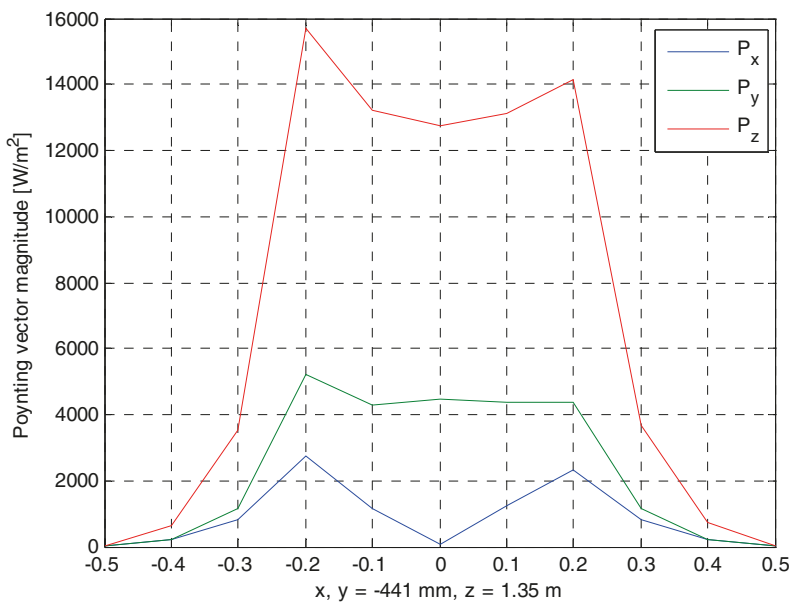

Figure 13. Power propagating in the $\mathrm{x}, \mathrm{y}$ and $\mathrm{z}$ direction at a point above the centre conductor, in front of the anechoic cone tips.

\section{MANUfACTURING}

The GTEM cell, pictured in Fig. 14 and 15, was constructed entirely from $2 \mathrm{~mm}$ thickness Aluminium 6082, with supporting angle irons at each seam. The $300 \times 300 \mathrm{~mm}$ access panel was shielded around the edges with an EMI gasket, and the ventilation windows covered with wire mesh of hole size much smaller than $30 \mathrm{~mm}\left(\lambda_{0} / 10\right.$ at $\left.1 \mathrm{GHz}\right)$. Dielectric support was provided by Eccostock SH14 in the centre of the plate, as well as at the apex. The resistively loaded tips (Fig. 16) were constructed by placing $2 \times 100 \Omega$ flange mount resistors in series at each tip, supported by FR4 printed circuit boards bolted to the back plane. This eliminated the need to solder directly on the aluminium casing.

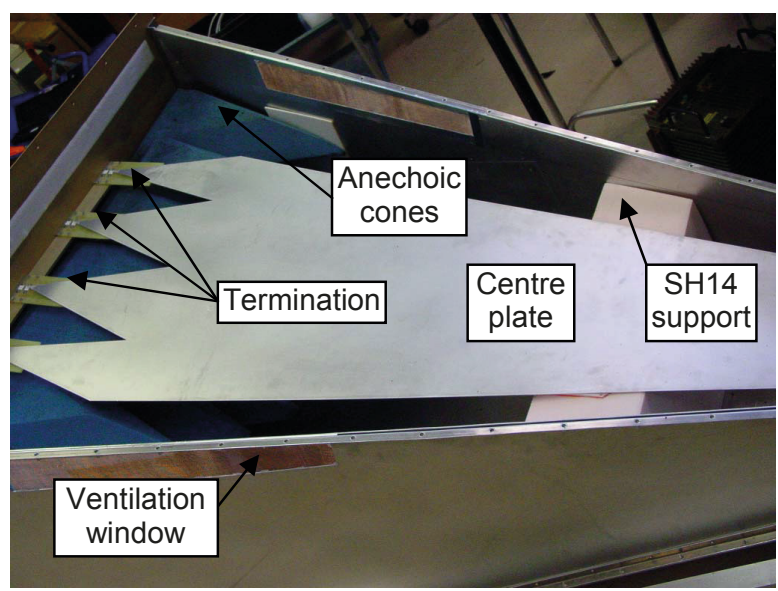

Figure 14. Manufactured GTEM cell, top cover removed.

To mitigate the effect of the input power incident on the top anechoic cones (Fig. 13), strips of Eccosorb HR10 were cut and mounted in cascade on top of the centre plate, in front of the top anechoic cones (Fig. 17)

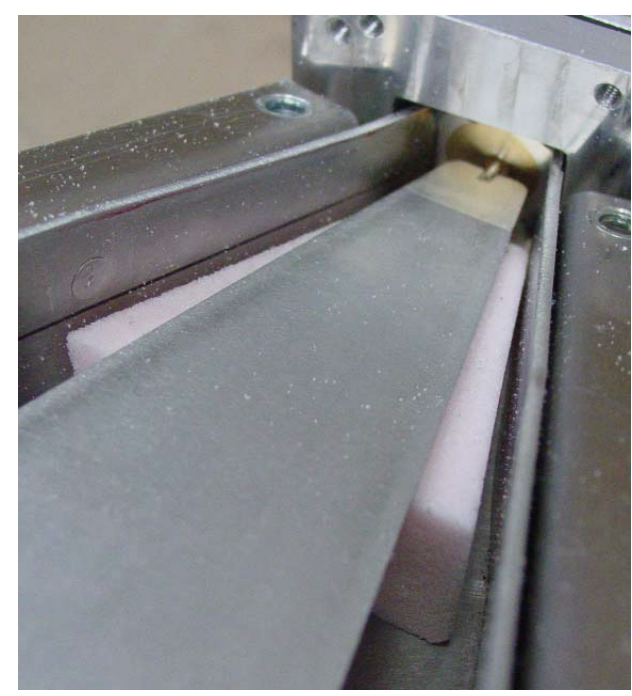

Figure 15. Apex of manufactured GTEM cell.

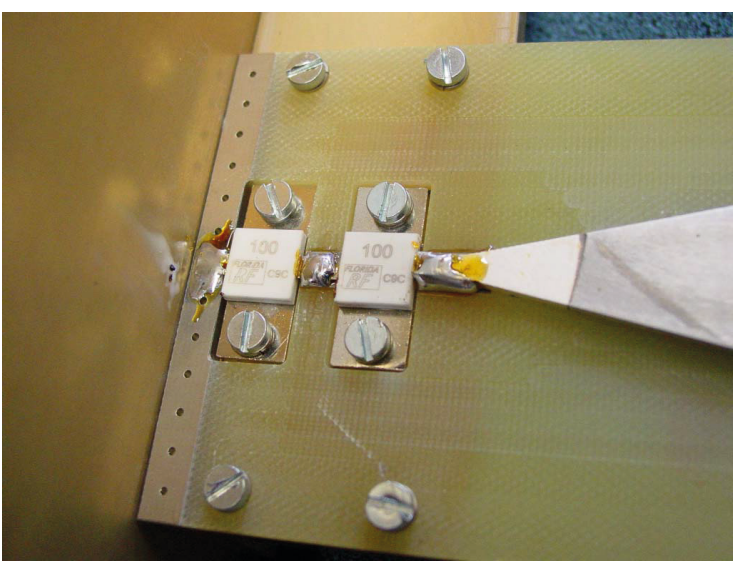

Figure 16. Detail of resistive termination.

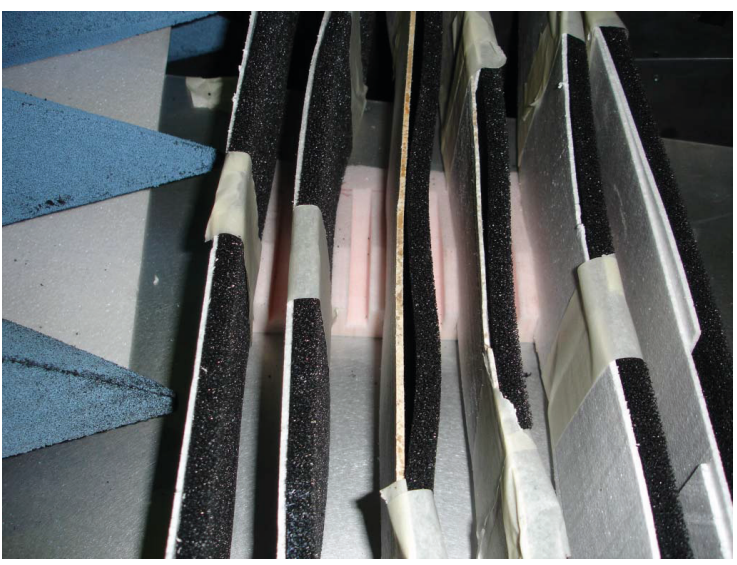

Figure 17. Six strips of HR10 mounted in front of the anechoic cones on top of the centre conductor. 


\section{QUALIFICATION}

The following qualification procedures were carried out on the GTEM cell before measurements commenced:

\section{A. Input reflection}

The input reflection (measured on a hand-held VNA, as photographed and shown in Fig. 18) was found to be below -15 $\mathrm{dB}$ across the band of interest. It was found that the addition of HR10 (excluded from the simulation model) changed the shape of the input reflection (compared to that in Fig. 7), but improved the input match at frequencies above $500 \mathrm{MHz}$.

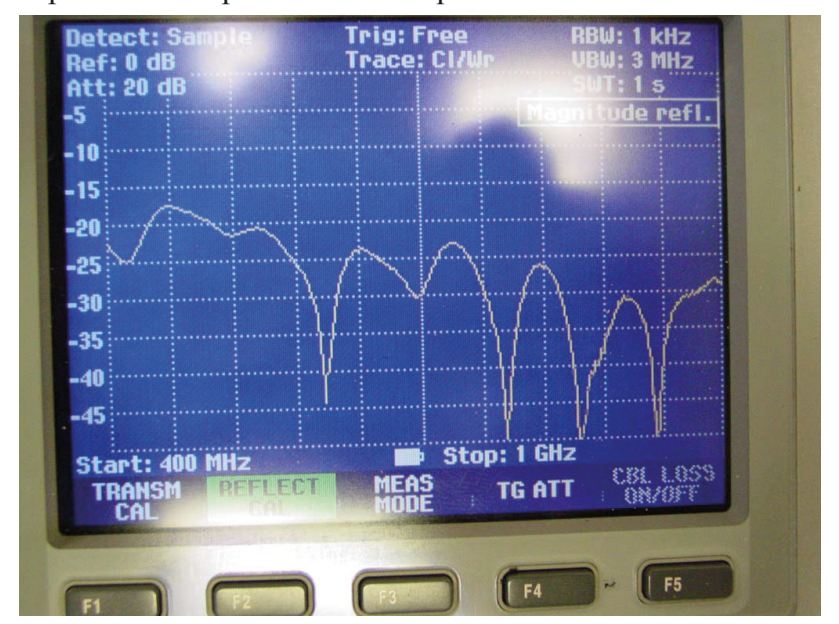

Figure 18. Measured input reflection.

\section{B. Nominal field strength}

The additional HR10 strips, by effecting a better propagating wave termination, also reduced standing wave patterns in the GTEM cell, lowering the effective local field strength in the test area (measurement shown in Fig. 19). The test area had to be moved towards the apex from the cell by $200 \mathrm{~mm}$ (to $\mathrm{z}=0.9 \mathrm{~m}$, Fig. 9) to achieve the required nominal $600 \mathrm{~V} / \mathrm{m}$. Feedback control was applied to regulate the output power on the cell to maintain this field strength across frequency. Under these conditions, the GTEM cell was successfully qualified.

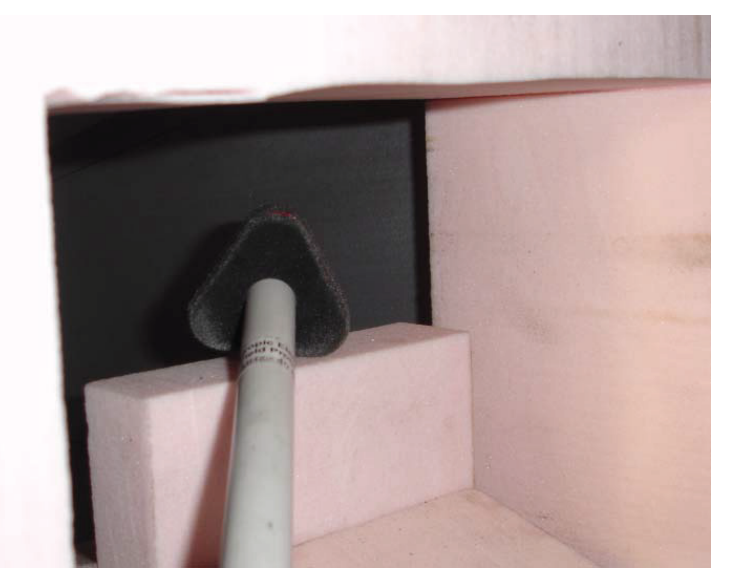

Figure 19. Measuring nominal field strength with a field probe.

\section{CONCLUSION}

This paper demonstrates the use of hybrid MLFMM-FEM simulation to design GTEM cells. The high required field strength and applied input power required significant power dissipation compensation. It is shown that a compact, in-house manufactured GTEM cell can achieve more than $600 \mathrm{~V} / \mathrm{m}$ field strengths.

\section{ACKNOWLEDGMENT}

The authors wish to thank Mel van Rooyen at EMSS (Pty) Ltd, South Africa, for extensive support with the FEKO modelling and simulation featured in the paper. This work was completed with support of Denel Dynamics, a division of Denel SOC Ltd, South Africa.

\section{REFERENCES}

[1] C. Icheln, "The Construction and Application of a GTEM Cell", Master's Thesis, Technical University of Hamburg-Harburg / Helsinki University of Technology, November 1995.

[2] S.-G. Xing, J. Li, S.-F. Li, and W.- J. Wang, "The simulation and experiment research on radiation of dipole antenna in GTEM cell", Proc. Int. Conf. Microwave and Millimeter Wave Technology (ICMMT), Chengdu, pp. 817 - 819, May 2010.

[3] X. T. I. Ngu, A. Nothofer, D. W. P. Thomas and D. W. P. Thomas, "A complete model for simulating magnitude and phase of emissions from a DUT placed inside a TEM cell”, IEEE Trans. EMC, vol. 49, no. 2, pp. 285 - 293, May 2007.

[4] Z. Junru, Z. Wensi, Y. Mengxia, and W. Yuanyuan, "Design of ultra wide band transition connector for GTEM cell", Proc. Int. Conf. Electronics, Communications and Control (ICECC), Ningbo, pp. 3657 3660, Sept. 2011.

[5] I. Wu, S. Ishigami, G. Gotoh, and Y. Matsumoto, "Effect on Electric Field of Foam Block in GTEM Cell”, Proc. IEEE Int. Symp. EMC, Austin, pp. 233 - 237, Aug. 2009.

[6] D. Hansen, D. Ristau, T. Spaeth, W. A. Radasky, K. S. Smith, and J. L. Gilbert, "Analysis of the measured field structure in a GTEM 1750”, Proc. IEEE Int. Symp. EMC, Chicago, pp. 144 - 149, Aug. 1994.

[7] S. Ghosh, R. Shingley, S. V. K. Shastry, and A. Chakrabarty, "Design and characterisation of GTEM Cell", Proc. Int. Conf. Electromagnetic Interference and Compatability, pp. 274 - 279, Dec. 1999.

[8] K. Malaric, J. Bartolic, and B. Modlic, "Absorber and resistor contribution in the GTEM-cell", Proc. IEEE Int. Symp. EMC, Washington D.C., vol. 2, pp. 891 - 896, August 2000.

[9] M. D. Judd and O. Farish, "A Pulsed GTEM System for UHF Sensor Calibration”, IEEE Trans. Instrum. Measurement, vol. 47, no. 4, pp. 875 -880, August 1998.

[10] H. X. Araujo, and L. C. Kretly, "Optimizing Impedance Matching between the Exciter - APEX and the GTEM Chamber", Proc. IEEE Convention of Electrical and Electronics Engineers in Israel (IEEEI), Eliat, pp. 986 - 990, Nov. 2010.

[11] D. Pouhe, and B. Maier, "Design and Simulation of a Mode Suppressed GTEM Cell", Proc. Int. Conf. Electromagnetics in Advanced Applications (ICEAA), Cape Town, pp. 1159-1164, September 2010.

[12] P.-M. Nicolae, I.-D. Nicolae, and D.-G. Stanescu, "Using GTEM Cells for Immunity Tests on Electronic Boards with Microcontroller", Proc. IEEE Int. Symp. EMC, Pittsburgh, pp. 44 - 49, Aug. 2012. 